
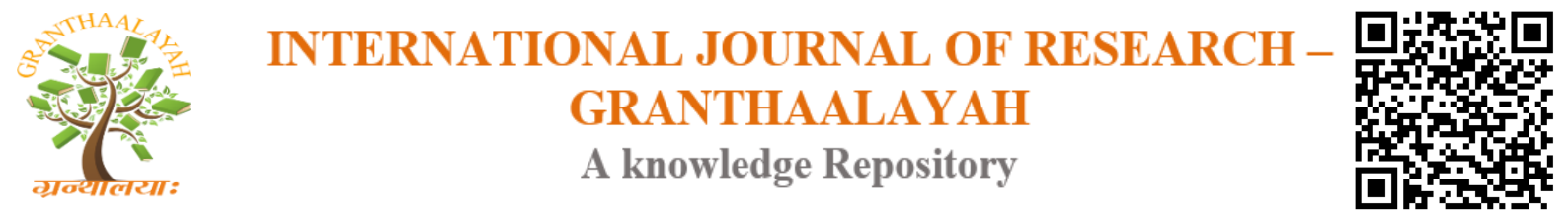

Science

\title{
MISSED OPPORTUNITIES OF IMMUNISATION AMONG CHILDREN BELOW 24 MONTHS VISITED ELMAK NIMIR TEACHING HOSPITAL, SUDAN 2016
}

\author{
Dr.Adam Dawria ${ }^{* 1}$, Dr.ali Mohieldin ${ }^{2}$, Dr.Fatima Alshehk ${ }^{3}$, Zamzam Omer Tutu ${ }^{4}$ \\ ${ }^{* 1}$ Assistant Professor PhD at King Khalid University College of Applied Medical Science \\ Public Health Department. WOH Independent Consultant \\ ${ }^{2} \mathrm{PhD}$, Associate Professor, King Khalid University, College of Applied Medical Science, \\ Departments of Public Health \\ ${ }^{3} \mathrm{PhD}$, Senior Lecturer at King Khalid University, College of Applied Medical Science, \\ Departments of Public Health \\ ${ }^{4}$ Public Health Officer at river Nile state, Atbara Locality
}

\begin{abstract}
Immunization has often been cited as one of the greatest medical success stories in human history. A cross-sectional hospital based study conducted from the period started from March 2016 to December 2016 .the study aimed to assess the missed opportunity of vaccine amongst under 24 months in Shendi locality, Total of 220 children under 2 years were been selected using convenience universal coverage for all children attending to the hospital seeking medical care, structured Questionnaire filed by their care givers. Our results revealed that, the prevalence of missed opportunity among the study population were $35 \%$ as aver all children examined, $20 \%$ for BCG, $23 \%$ (Penta, Rota and polio vaccines), $40 \%$ for Measles 1 st dose and $60 \%$ for Measles 2nd dose. These results show high percentage of dropout due to the missed opportunity from the main hospital in the Shendi locality. The main recommendations of our study are, institute primary health care unit to provide immunisation services in the teaching hospital and this is will minimize the gab of vaccine missed opportunity, implement intensive health education programme to the local community especially rural community.
\end{abstract}

Keywords: Immunisation; Missed Opportunity; Children; Hospital.

Cite This Article: Dr.Adam Dawria, Dr.ali Mohieldin, Dr.Fatima Alshehk, and Zamzam Omer Tutu. (2017). "MISSED OPPORTUNITIES OF IMMUNISATION AMONG CHILDREN BELOW 24 MONTHS VISITED ELMAK NIMIR TEACHING HOSPITAL, SUDAN 2016." International Journal of Research - Granthaalayah, 5(10), 51-58. https://doi.org/10.29121/granthaalayah.v5.i10.2017.2267. 


\section{Introduction}

As early as 1983, the Expanded Programme on Immunization (EPI) has recommended using every opportunity to immunize all eligible people as a direct strategy to increase vaccination coverage. Protocols for the assessment of "missed opportunities" (defined as any contact with a health service that did not result in an eligible child or woman receiving the needed vaccines) were developed in 1984 and 1988 and widely distributed.

Missed opportunities for vaccination occur in two major settings:

- During visits for immunization and other preventive services (e.g. growth monitoring, nutrition assessments and oral rehydration training sessions, etc.).

- During visits for curative services.

In both settings, eliminating missed opportunities has the potential to raise immunization coverage in a population, particularly when the availability and use of health services is high. When the availability and use of health services is low, immunizing at health care contact is extremely important because the risk for vaccine-preventable diseases is likely to be high in these areas ${ }^{(1)}$.

Immunization has often been cited as one of the greatest medical success stories in human history. Research has repeatedly demonstrated that immunization is one of the most effective medical interventions to prevent disease. In fact, research shows that with the exception of clean drinking water, no other human intervention surpasses the impact immunizations have had on reducing infectious disease and mortality rates-not even antibiotics. Many diseases are preventable through immunization. Since the introduction of vaccines, rates of diseases such as measles, mumps, rubella, polio, diphtheria, whooping cough (pertussis), and Haemophilus meningitis have declined by over 95 per cent. Currently, immunizations are estimated to save three million lives per year worldwide ${ }^{(1)}$.

Vaccination is regarded as one of the greatest public health achievements of the 20th century and one of the most cost-effective preventive services for children. Vaccination has substantially reduced the global burden of infectious diseases. The major contributor to this successful achievement is the Expanded Program of Immunization (EPI) of the World Health Organization (WHO) and Global Alliance Vaccine Initiative (GVAI), which was launched in 1974 as a worldwide alliance of collaborating nations and its goal was to expand immunization service and coverage $^{(2)}$.

Missed opportunities for the immunization constitute obstacles to raising immunization coverage among children. An opportunities of immunization is missed when a child who eligible for immunization and who has no contraindications to immunisation visit a health service and doesn't received all needed vaccine ${ }^{(3)}$. Inadequate levels of immunization against childhood diseases remain a significant public health problem in resource-poor areas of many countries in Africa. The reasons for incomplete vaccination and non-uptake of immunization services are poorly understood ${ }^{(4) .}$ The success of EPI dose not only depends on effective vaccination series, but also high immunization coverage. Estimate of immunization coverage that based on vaccination status of children in specific age or with specific demographic characteristic. For 
example, first dose of measles (MCV1) is used to monitor progress toward the Millennium Development Goals and third dose of DPT coverage is used as an indicator of health system performance in other countries ${ }^{(2)}$. Pinpointing the non-vaccination determinants is important for achieving the EPI target. The initiation and completion such as caregivers' education, experience with previous immunization service, adequate information on vaccination, immigration, socioeconomic status, and so on. Failure to be vaccinated on time would also increase the susceptible period of children, thus limiting the herd immunity. This problem was illustrated in a large measles epidemic in the USA during 1989-1991, where delayed vaccination of MCV was identified as one of the main cause ${ }^{(2)}$.

Particularly when the availability and use of health services are high. When the availability and use of health services are low, immunizing at every health care contact is extremely important because the risk for vaccine-preventable diseases is likely to be high in these areas. Since 1984, EPI has been promoting the use of a standard survey for assessing missed opportunities for immunization. In 1987, when the results from several surveys in developing countries indicated that the majority of children attending curative care facilities were missing opportunities to be immunized, the Global Advisory Group called for more surveys to investigate the magnitude of the problem among children and women of childbearing age and to identify strategies to reduce missed opportunities ${ }^{(5)}$. Reducing missed opportunities is the easiest and immediate remedy to improve vaccine coverage at no extra cost, by exploiting existing resources. There is, therefore, an urgent need to examine the magnitude and factors responsible for Reducing missed opportunities, to rapidly achieve the National immunization targets ${ }^{(6)}$.

\section{Methodology and Study Material}

\subsection{Missed Opportunity Survey}

A missed opportunity survey to assess whether all clients who were present in a facility providing vaccinations for which they were eligible that day received them up to date. the survey includes reviews of coverage data and patient registers and interviews with clients as they leave health facilities ${ }^{(7) \text {. }}$

\subsection{Study design}

A cross-sectional hospital based survey conducted from the period started from March 2016 to December 2016.

\subsection{Study area}

Shendi or Shandi is a town in northern Sudan, situated on the east part of the Nile River $150 \mathrm{~km}$ northeast of Khartoum. Shandi is also about $45 \mathrm{~km}$ southwest of the ancient city of Meroe. Located in the River Nile state, Shandi is the center of the Ja'aliin tribe and an important historic trading center. The total population estimated is 55516 .

Elmak Nimir hospital is a one of major referral hospital in river Nile state as well as teaching hospital under administrative of shendi university faculty of medical and surgery .the hospital 
consist of the main departments, including medicine ,surgery ,paediatrics and obstetric in additional to specialization services to the heart and renal failure patients. The total bed capacity is (235) divided for (5) ward included infant malnutrition therapy ward. The hospital doesn't has any PHC packages specially vaccination services and growth monitoring.

\subsection{Sample Size and Sampling Technique}

Total of 220 children under 2 years were been selected using convenience universal coverage for all children attending to the hospital seeking medical care. all participants were well responded , the inclusion criteria was any child not permanently reside in shendi locality or came before three months, mothers with twin baby only one child was selected ,the interview is only applied for caregiver more than 18 years.

\subsection{Data Analysis}

Data was analysed using SPSS and Excel micro soft sheet, then the significant was tested by using the p.value.

\subsection{Ethical Consideration}

Prior consent was cleared from the Elmak Nimer teaching hospital as well as all the children`s care giver participated in the study.

\section{Result}

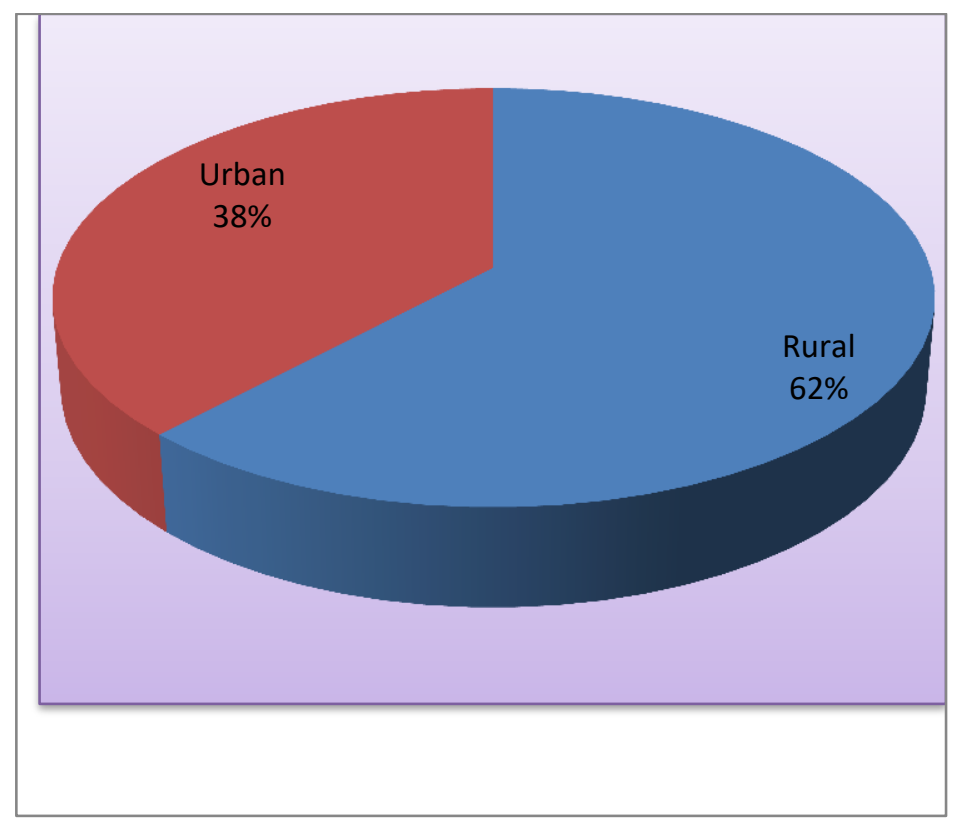

Figure 1: The distribution of the participant by their resident area in Emak Nimir hospital shendi locality 2016. 


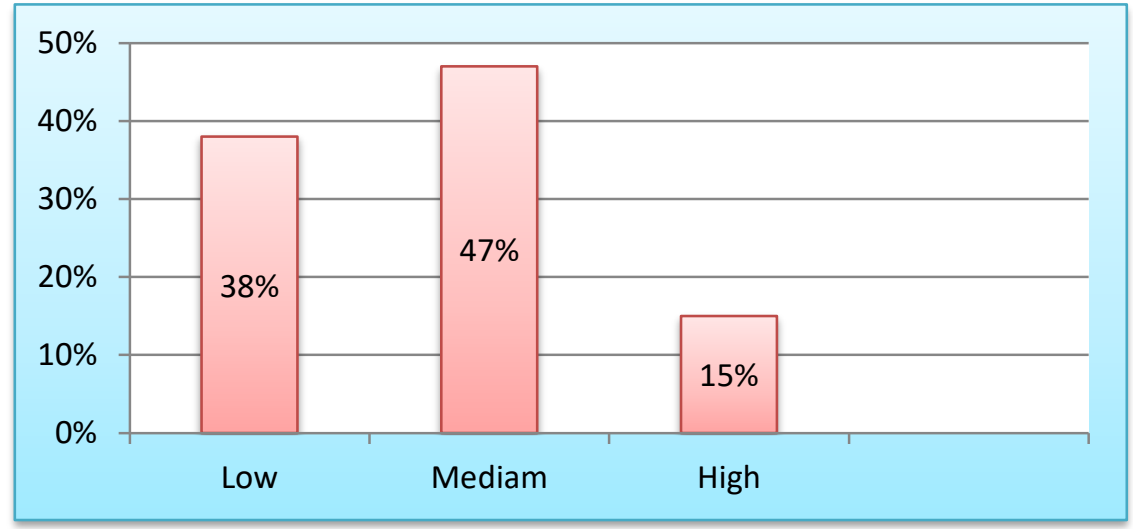

Figured 2: The economical level among the participants in Emak Nimir hospital -shendi locality 2016.

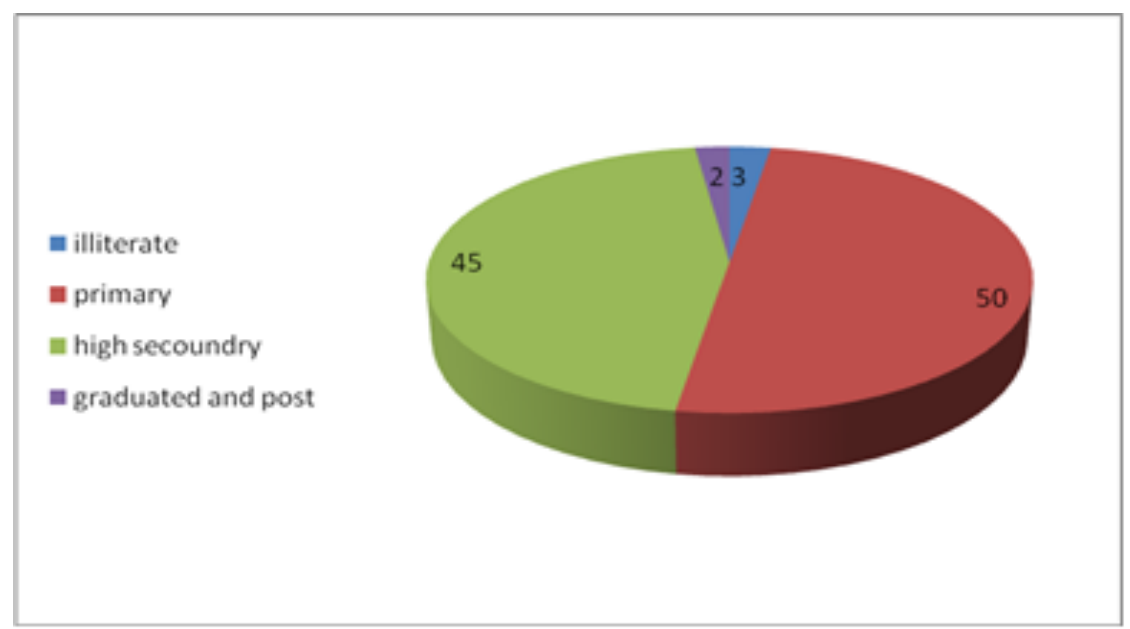

Figure 3: Distribution of educational level of the study population in Shendi locality_ Sudan 2016

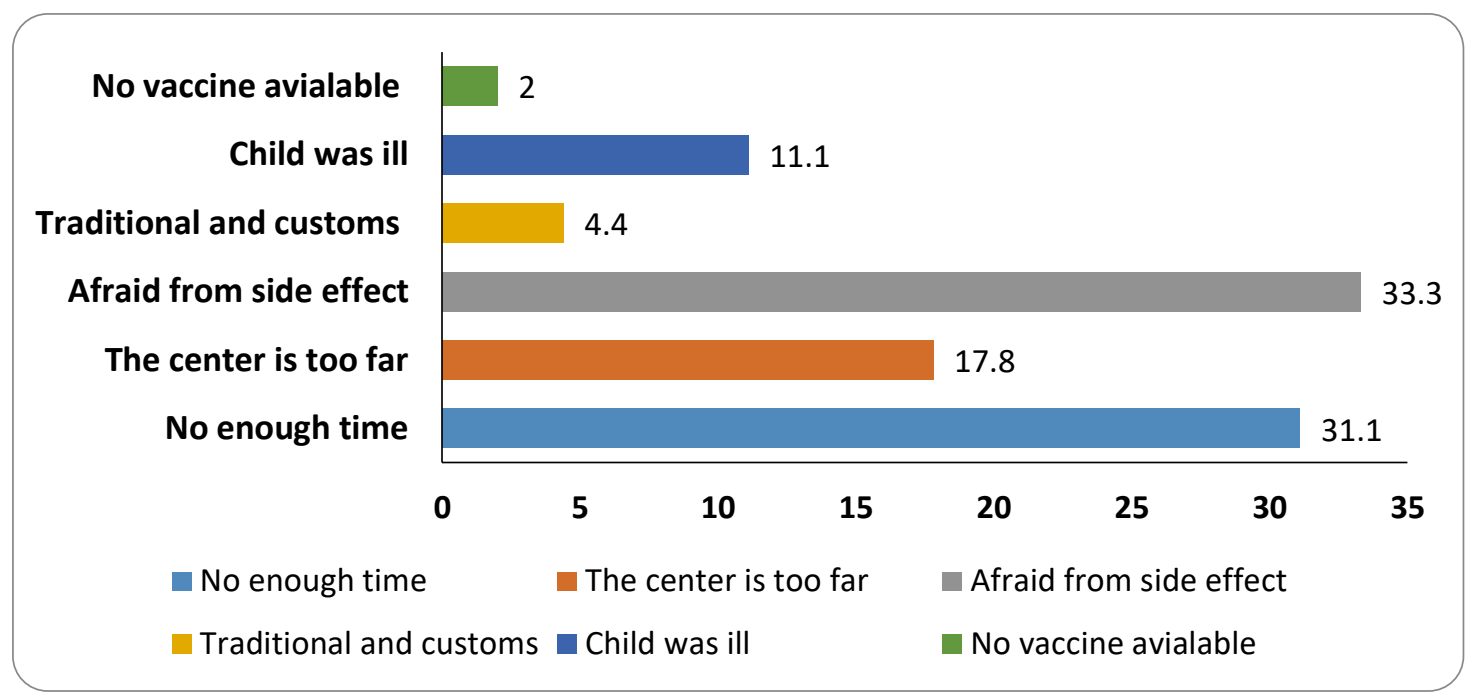

Figure 5: The reason behind incomplete of the vaccination course among study population in Shendi locality_Sudan 2016. 


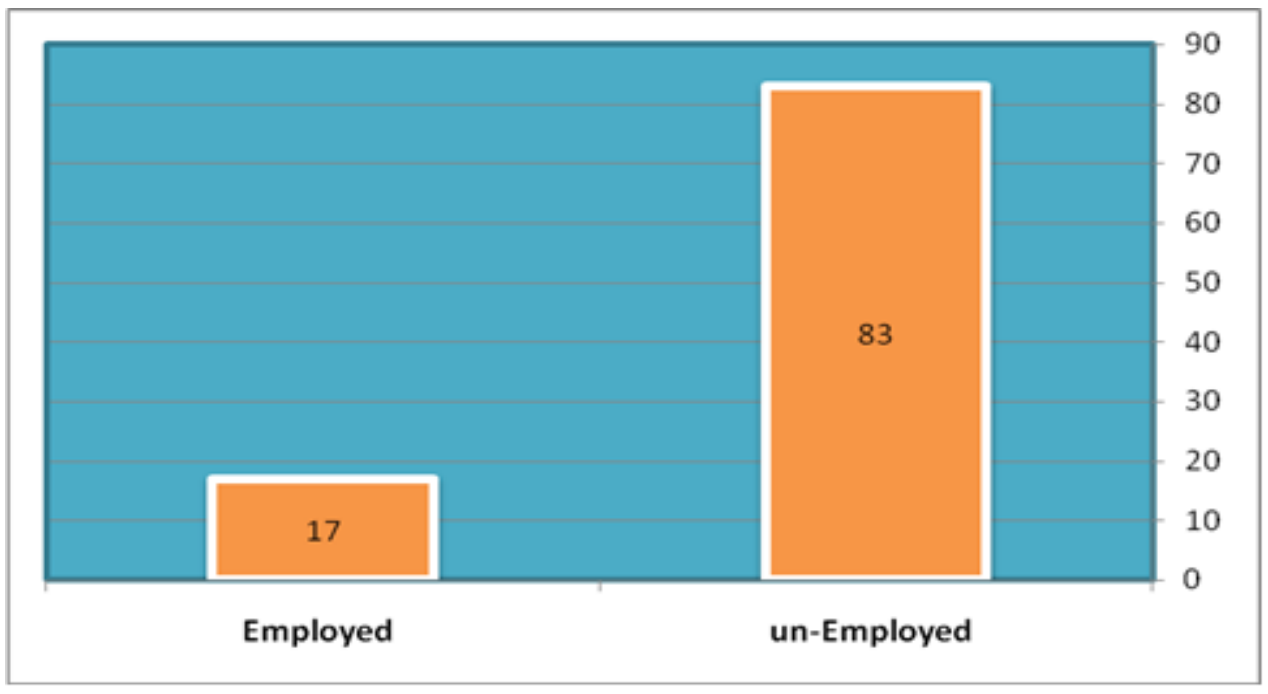

Figure 6: The percentage of employment status within study population in Shendi locality _ Sudan 2016.

Table 1: Vaccination status with children profile and accessibility status, Shendi locality -Sudan 2016.

\begin{tabular}{|c|c|c|}
\hline Variables & Frequency & Percent \\
\hline \multicolumn{3}{|c|}{ The distance to the health facilities (accessibility) } \\
\hline Less than $5 \mathrm{Km}$ & 146 & 48.9 \\
\hline More than $5 \mathrm{Km}$ & 148 & 51.1 \\
\hline \multicolumn{3}{|c|}{ Age profile of selected children } \\
\hline$<1$ year & 143 & 43 \\
\hline From 1 to 2 years & 120 & 20 \\
\hline$>2$ years & 137 & 37 \\
\hline \multicolumn{3}{|c|}{ Vaccination status (Drop out Preverlance) } \\
\hline BCG & 79 & 80 \\
\hline Polio ,Rota,Penta & 76 & 77 \\
\hline Measles 1 & 75 & 60 \\
\hline Measles 2 & 84 & 30 \\
\hline
\end{tabular}

\section{Discussion}

The prevalence of missed opportunity among the study population were $35 \%$ as aver all children examined, $20 \%$ for BCG, $23 \%$ (Penta, Rota and polio vaccines), $40 \%$ for Measles $1^{\text {st }}$ dose and 
$60 \%$ for Measles $2^{\text {nd }}$ dose (first dose of measles (MCV1) is used to monitor progress toward the Millennium Development Goals and third dose of DPT coverage is used as an indicator of health system performance in other countries ${ }^{(2)}$ ). These results shows high percentage of dropout due to the missed opportunity from the main hospital in the Shendi locality. The increasing of the number of missed opportunity, polio in particular is a bad sign agonist the polio eradication program; therefore it could lead to decrease the level of the herd immunity among the vulnerable group in study population. World Health organization (W.H.O) estimated the prevalence of the global immunisation missed opportunity as $42 \%$ and this is comes closer to our study findings.

Among the study population there were 33 illiteracy and $13 \%$ were graduated and above. But our statistical analysis doesn't show any statistical significant between the level of education and vaccination status (P-value 0.75). there was significant association between resident location (Pvalue 0.03 ), as we found that the percentage of the drop out among the rural population is higher than urban population, these could be belong the shortage of the coverage by mobile teams due to the shortage of resources in the local authority levels, Other researchers have also reported similar findings in Northern Nigeria, Indonesia and south Sudan ${ }^{(1)(4)(6)}$.

The utilization of immunisation services was good according to our results as we only noted $2 \%$ percentages mentioned that the vaccine was not available in the health centre during their visits for vaccination. By the other hand we found that the factors regarding accessibility is existence, therefore $17.8 \%$ of the participants crossing more than $5 \mathrm{~km}$ to access the health services for immunization. This is could lead to the increasing numbers of defaulters among the children and it is not met the $\mathrm{WOH}$ recommendation on reach each children (District) approach (RED Approach) .also anther factors revealed from the awareness and knowledge of the care givers shows about $33.3 \%$ were afraid from the side effect of the shot, $31.1 \%$ showed that there was no enough time to reach the health centre and this this reflect the low priority of immunisation in their live. This is could be managed by increasing the health education programme along with activate the intensive home visit program to detect the defaulters.

\section{Conclusion and Recommendation}

Our study revealed that high missed opportunity level was noted in the main general educational hospital, the most reasons behind the absent of doses able to be managed to address the issue. The main recommendations of our study are, institute primary health care unit to provide immunisation services in the teaching hospital and this is minimize the gab of vaccine missed opportunity, local heath authority should established intensive health education programme to the local community especially rural community .another focus should be paid to the home visit activities to sensitised the local community to complete their vaccine course up to date.

\section{Acknowledgements}

Deep and honourable Thanks passed to the local public health administration regarding the continues collaborations were offered. Special thanks to the medical manager of the teaching hospital and immunisation officer Mr.Ibrahim Khalid for their close and find support during the duration of the study. Lastly our thanks to my colleagues in the department of public health in king Khalid university for their assistant in reviewing our works. 


\section{References}

[1] David Gittelman, Marty Makinen. Immunisation Essential, A practical Field Guide. s.1.: USAID, 2010. ISBN 0-9742991-2-X.

[2] Missed Immunization Opportunities among children in Enugu. B N Tagho, Conwuasigwe. 32, Abuja: Nigerian Journal of Pediatrics, 2005, Vol. 4. 73-76.

[3] Completeness and timeliness of vaccination and determinants for low and late uptake among young children in eastern China. Yu Hu1, *, Yaping Chen1, Jing Guo1, Xuewen Tang1, and Lingzhi Shen1. Issue 5, China: Human Vaccines \& Immunotherapeutics, 2014, Vol. Volume 10. $1408-1415$.

[4] Reasons for incomplete vaccination and factors for missed opportunities among rural Nigerian children. Abdulraheem I. S.1*, Onajole A. T.2, Jimoh A. A. G.3 and Oladipo A. R.4. ISSN 21412316 (C2011 Academic Journals, Nigeria: Journal of Public Health and Epidemiology, April 2011, Vols. Vol. 3(4), pp. 194-203, April 2011. 194-203,.

[5] Studies of missed opportunities for immunization in developing and industrialized countries. S.S. Hutchins, 1 H.A.F.M. Jansen, 2 S.E. Robertson,3 P. Evans,. Reprint No. 5414, WHO, Geneva, Switzerland. : Bulletin of the World Health Organization, , 1993, Vol. 71 (5):. 549-560 (1993).

[6] An Observational, Health Service Based Survey for Missed Opportunities for Immunization. MAMTA MURANJAN, CHHAYA MEHTA,*ABHIJIT PAKHARE. AUGUST 17, 2011, India: INDIAN PEDIATRICS, 2011 May 30. PII: S09747559INPE000272-2, Vol. VOLUME 48 933-936.

[7] Alberta. Alberta Immunization strategy 2007-2017. Vaccine prevantable diseases Immunzations, minisstry of health and wellness. s.1.: Alberta Health and Wellness, 2007. pp. 2-7, technical report. ISBN: 0-7785-3502-9.

[8] Orginization, World Health. Immunization, Vaccines and Biologicals. World Health Orginization. [Online] W.H.O, May 23, 2016. [Cited: jun 12, 2016.] Informations sited under the proposal grant request.

http://www.who.int/immunization/rfp_review_missed_opportunities_vaccination/en/.

*Corresponding author.

E-mail address: aabdelqader@ kku.edu.sa 